\title{
NEUROLOGICAL PARANEOPLASTIC SYNDROMES IN EDUCATION AND NEUROLOGICAL PRACTICE
}

\author{
Deleva N.

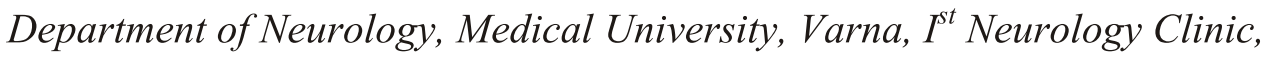 \\ MHAT "Sveta Marina", Varna
}

Reviewed by: Prof. D. Minchev, MD, PhD, DSci

\begin{abstract}
The neurological involvement in paraneoplastic syndromes is a result of the effect on the nervous system of an occult or diagnosed and treated neoplastic disease. Nearly $20 \%$ of patients, suffering from malignant neoplasm, develop neurological complications other than pain, mainly due to tumor invasion, drug or radiotherapeutical neurotoxicity, metabolic, vascular or infectious factors. Regardless of the fact that the primary approach in diagnosing neurological paraneoplastic syndromes is clinical, routine neurological competence is not sufficient. Neurological paraneoplastic syndromes are subject to particular educational and clinical interest by the neurooncological community, represented by a number of national and international institutions. These problems took place as well in the activities plan of the Neurooncological Council of EFNS and EANO. In response to the challenge, the special committee on education at the EFNS carries out large-scale activities. The obligatory, considering its disciplinary character, and beneficial collaboration between neurologists, oncologists, radiologists, and other specialists involved, does not compensate the necessity for qualified neurooncological thinking and behavior. Analyzing the different organization of neurooncological assistance in each EU country, the most correct conclusions for changes in the status of neurooncology in education and clinical practice are being sought.
\end{abstract}

The neurological involvement in paraneoplastic syndromes is a result of the effect on the nervous system of an occult or diagnosed and treated neoplastic disease. Nearly $20 \%$ of patients, suffering from malignant neoplasm, develop neurological complications other than pain, mainly due to tumor invasion, drug or radiotherapeutical neurotoxicity, metabolic, vascular or infectious factors. $(1,2,3,4)$

Regardless of the fact that the primary approach in diagnosing neurological paraneoplastic syndromes is clinical, routine neurological competence is not sufficient. (5)

Neurological paraneoplastic syndromes are subject to particular educational and clinical interest by the neurooncological community, represented by a number of national and international institutions. These problems took place as well in the activities plan of the Neurooncological Council of EFNS and EANO. In response to the challenge, the special committee on education at the EFNS carries out large-scale activities.

A number of consensus guidelines for the diagnosis and treatment of many neurological diseases and conditions have been published by specialized scientific councils and

Address for correspondence:

N. Deleva, Dept. of Neurology, Medical University, 55 Marin Drinov

St, BG-9002 Varna, BULGARIA

E-mail: ind@varna.techno-link.com workgroups of EFNS, especially in domains where significant progress has been achieved.

The importance of neurological paraneoplastic syndromes in education and neurological practice has been demonstrated by the report published in the European Journal of Neurology in 2006, 13, 682- 690, and presented at the Xth Congress of EFNS (EFNS Task Force article): Management of paraneoplastic neurological syndromes: report of an EFNS Task Force. C.A.Vedeler, J.C. Antoine, B.Giometto, F.Graus, W.Grisold, I.K. Hart, J. Honnarat, P.A.E. Sillevis Smitt, J.J.G.M. Verschuuren and R.Voltz for the Paraneoplastic Neurological Syndrome Euronetwork.

For the last few years, the Bulgarian Association of Neuro-Oncology (BANO) and the Bulgarian Scientific Society of Neurology have been carrying out a programme, coordinated with our European partners for improvement in neurooncological education and clinical practice.

The Department of Neurology and the Medical University in Varna in coordination with the Bulgarian Scientific Society of Neurology have accomplished pioneer activities to organize international neurooncological meetings with scientific, but basically didactic goals, directed at improving the qualification of graduated physicians, specialists in neurology, neurosurgery, oncology, radiology and pathology. 
The First International BANO Meeting took place between 8 and 10 November 2002 in Varna, Bulgaria. The scientific programme included a postgraduate course with lectures on the use of antiepileptics in neuro-oncology (J. Hildebrand), brain metastases (R. Soffietti), cancer and nervous system (W. Grisold), palliative care (S. Oberndorfer). A round table was organized on the role of neurologists in neuro-oncology, with N. Deleva (Bulgaria); M. Gavriliuc (Moldova); Y. Karatkevich (Belarus); I. Shmakova (Ukraine), participants from Russia, Macedonia, Turkey.

The Second International BANO Meeting was held between 5 and 7 November 2004 in Varna, Bulgaria. The teaching course on neurotoxicity (W. Grisold), clinical symptoms in cancer patients (J. Hildebrand), palliative care (S. Oberndorfer), classification of CNS tumors (Nachev), etc. was an essential part of the programme. A mini symposium on neuropathic pain was organized, moderated by P. Shotekov. All materials have been published in Scripta Scientifica Medica, 2006, 36, suppl. 2.

The organization of both neurooncological meetings and the education activities included have been extremely well estimated in the bulletin of the Neurooncological Scientific Council of EFNS and endorsed by the Crediting Committee.

The importance of the elaboration of new concepts and approaches in neurooncological education might be considered in the context of the newest methods for achieving the most correct and closest attitude towards the education of students, physicians and the clinical neurological practice, specifically changes, including feedback-based education. In a study by N.R. Cohen et al (What should junior doctors be competent in, with respect to the neurological sciences?), published in 2006 in the European Journal of Neurology, aimed at defining consensus statements regarding the point of view and the preferences of students, junior physicians and experts, an interview is used, consisting of questions concerning the significance and necessity to present theoretical knowledge and education in specific skills and abilities. The study has been accomplished by means of a specially developed component for Neurosciences and with the resources of the International Virtual Medical School, IVIMEDS, based at Dundel UK.

The obligatory, considering its disciplinary character, and beneficial collaboration between neurologists, oncologists, radiologists, and other specialists involved, does not compensate the necessity for qualified neurooncological thinking and behavior. Analyzing the different organization of neurooncological assistance in each EU country, the most correct conclusions for changes in the status of neurooncology in education and clinical practice are being sought.

The position of neurologists in neurooncology during the last years, in the course of cardinal changes in diagnostics and treatment of neurooncology patients, has been increasingly considered as related to the domain of neurological paraneoplastic syndromes.

Aims of the education: Conclusions

- Accent should be put on these parts of the programs of some preclinical and all clinical disciplines, which refer to possible cases of neoplastic, iatrogenic and paraneoplastic involvement of the nervous system.

- Education in the course of neurooncology should be balanced by imposing a sense of an integral oncological process, thus creating a base for clinical thinking in students.

- Paraneoplastic syndromes should be brought to a higher level in differential diagnostic hierarchy, having in mind the role of the neurologist for their early diagnosis and adequate treatment.

- Possibilities should be created for continued postgraduate education on neurooncology, in an attempt to integrate neurophysiological and neuroimmunological options with the clinical paradigm.

- Education should be carried out in the spirit of elimination of prejudices and stigmata, connected with oncological diseases.

\section{REFERENCES}

1. Grisold, W., Krauseneck, P., Muller, B. Praktische Neuroonkologie. Wien, New York: Springer, 2000, 609 pp.

2. Hauser, S. (Ed.) Harrison's Neurology in Clinical Medicine. New York: McGraw-Hill, 2006, 692 pp.

3. Hildebrand, J., Brada, M. Differential Diagnosis in Neuro-oncology. Oxford: Oxford University Press, 2001, 298 pp.

4. Royden Jones, H., Netter, F., Beker, R. Netter's Neurology. Teterboro, NJ: Icon Learning Systems, 2005, 980 pp.

5. Vedeler, C., Antoine, J., Giometto, B., Graus, F., Grisold, W., Hart, I., Honnorat, J., Sillevis Smith, P., Verschuuren, J., Voltz, R. Management of paraneoplastic neurological syndromes: report of an EFNS Task Force. Eur J Neurol. 2006, 13, 682-690. 